\title{
Mechanical stress influences the viability and morphology of human parametrial ligament fibroblasts
}

\author{
MING HU, LI HONG, SHASHA HONG, JIE MIN, YANG ZHAO, QING YANG, \\ QIFAN ZHANG, JIANMING TANG and YANG LI
}

\begin{abstract}
Department of Gynaecology and Obstetrics, Renmin Hospital of Wuhan University, Wuhan, Hubei 430060, P.R. China
\end{abstract}
Received November 10, 2015; Accepted November 14, 2016

DOI: $10.3892 / \mathrm{mmr} .2016 .6052$

\begin{abstract}
The present study aimed to investigate damage to human parametrial ligament fibroblasts by detecting cell proliferation, cytoskeletal structure, cellular alterations and senescence. Uterosacral and cardinal ligaments were obtained from 10 patients with cervical intraepithelial neoplasia grade II-III, who had received total vaginal hysterectomies, and fibroblasts were derived from this tissue. Fibroblasts were stretched using a four-point bending system with a force of 0 (control), 1,333 $\mu$ strain $(1 \mathrm{~mm})$ or $5,333 \mu$ strain $(4 \mathrm{~mm})$ for $4 \mathrm{~h}$. The present study revealed that mechanical force significantly reduced cell proliferation and increased cell senescence. As mechanical force increased, the mitochondria of fibroblasts began to exhibit vacuolization, and the cell cytoskeleton began to depolymerize and rearrange. In conclusion, the present study demonstrated that mechanical forces within a certain range may induce cell damage via mitochondrial injury, cytoskeletal alterations and increased cell senescence, resulting in decreased cell viability of pelvic fibroblasts.
\end{abstract}

\section{Introduction}

Pelvic organ prolapse (POP) is a common form of female pelvic floor dysfunction. Pregnancy, childbirth, obesity and constipation, which may lead to the increase of abdominal pressure, are considered to be important risk factors for POP (1-4); mechanics serve a vital role in the incidence of POP. Further studies suggest that the occurrence of POP may be associated with an imbalance of the oxidation-reduction equilibrium in vivo $(5,6)$. Our previous study demonstrated that the expression levels of antioxidant enzymes in the pelvic tissues of patients with POP was significantly decreased, which indicates that oxidative stress is closely associated with

Correspondence to: Dr Li Hong, Department of Gynaecology and Obstetrics, Renmin Hospital of Wuhan University, 238 Jiefang Road, Wuhan, Hubei 430060, P.R. China

E-mail: drhongli7777@gmail.com

Key words: mechanical strain, fibroblasts, cell viability, mitochondria, cytoskeleton, cell senescence, pelvic organ prolapse the occurrence of POP (7). In addition, this study revealed that a specific range of mechanical forces may cause an increase in reactive oxygen species (ROS) in human parametrial ligament fibroblasts (HPLFs) (8). Therefore, it was hypothesized that mechanical forces may damage cells by inducing oxidative stress, furthering the development of POP.

The activity and proliferation of cells, which reduce when cells are subjected to external injury, is an important indicator of the cell state (9). While suffering from external damage, the cytoskeleton may depolymerize and rearrange to adapt to external stimuli (10). In cells, the mitochondria are the primary production site of active oxygen, and therefore exhibit the clearest damage upon increased oxidative stress. Furthermore, cellular senescence is a process consisting of the repair of DNA damage, mitochondrial energy metabolism and gene regulation (11). Therefore, the present study derived fibroblasts from female parametrial ligaments. Cell proliferation, cytoskeletal structure, mitochondrial morphology and cellular senescence were subsequently analyzed to investigate whether mechanical force may induce damage to the internal structure of the cell, and to examine the underlying mechanisms of the effects of mechanical stress on the occurrence of POP.

\section{Materials and methods}

Materials. A total of 10 patients with cervical intraepithelial neoplasia grades II-III from June 2014-June 2015 in Renmin Hospital of Wuhan University, who had received a total vaginal hysterectomy, were selected for the present study. Patients who had received estrin treatment within the past three months were excluded. Uterosacral ligaments and cardinal ligaments were obtained from patients following the receipt of informed consent. This study was approved by the Ethics Committee of Renmin Hospital of Wuhan University (Wuhan, China).

The present study employed a modified enzyme digestion method, as previously described (12) to obtain HPLFs. The tissue $(0.5 \times 0.5 \times 0.2 \mathrm{~cm})$ was placed into the Dulbecco's modified Eagle's medium (DMEM; Hangzhou Gino Biological Pharmaceutical Co., Ltd., Hangzhou, China) immediately following surgery, and was incubated at $4^{\circ} \mathrm{C}$ within $30 \mathrm{~min}$. The tissue was subsequently washed with phosphate-buffered saline (PBS) containing $100 \mathrm{KU} / \mathrm{ml}$ penicillin $\mathrm{G}$ and $100 \mathrm{mg} / \mathrm{ml}$ streptomycin (Hangzhou Gino Biological Pharmaceutical Co., Ltd.), and sectioned into small pieces. Following this, it 
was digested with $1 \%$ collagenase-I (Invitrogen; Thermo Fisher Scientific, Inc., Waltham, MA, USA) for $3 \mathrm{~h}$ at $37^{\circ} \mathrm{C}$ in $5 \% \mathrm{CO}_{2}$, followed by further digestion with $0.25 \%$ trypsin (Sigma-Aldrich; Merck Millipore, Darmstadt, Germany) for 5 min. Fetal bovine serum (FBS; 2 ml; Gibco; Thermo Fisher Scientific, Inc.) was used to terminate digestion. DMEM containing $15 \%$ FBS was slowly added to the culture flask. The medium was replaced every two days and the primary HPLF cells were cultured. Cells at passage 2-3 were considered to be relatively pure; these primary cells were identified as fibroblasts in our previous study (13). HPLFs at passage 4-7 were used for subsequent experiments.

Mechanical tensile strain. Fibroblasts were loaded with mechanical strain using a four-point bending device (Chengdu Miracle Technology Co., Ltd., Chengdu, China), which was divided into three parts: Mechanical power systems, a host computer and a strain-loading dish. The deformation displacement, loading frequency and loading time were set via the host computer. An engine was used to generate a mechanical force, which exerted strain onto Petri-dishes containing cells via a stamping motion. Once the Petri-dish was buckled, a corresponding force was exerted on the cells in the Petri-dish.

Fibroblasts at passage 4-7 were subjected to the loading strain. Cells were digested with $0.25 \%$ trypsin plus EDTA (Sigma-Aldrich; Merck Millipore). DMEM containing 15\% FBS was subsequently added to the cell pellet, following centrifugation ( $200 \mathrm{x}$ g at room temperature for $8 \mathrm{~min}$ ), to obtain the cell suspension. The cell suspension $\left(1.5-2 \times 10^{5}\right.$ cells $/ \mathrm{ml}$, $1.5 \mathrm{ml}$ ) was evenly spread onto the rat tail collagen-precoated culture plate (Sigma-Aldrich; Merck Millipore), which was incubated in $5 \% \mathrm{CO}_{2}$ at $37^{\circ} \mathrm{C}$ for $24 \mathrm{~h}$. Following this, the adherence of cells was observed. Once the cell volume was $\sim 80 \%$ of whole culture plate, cells were transferred to a strain-loading dish for mechanical strain testing.

Parameters were set to a frequency of $0.1 \mathrm{~Hz}$ and a duration of $4 \mathrm{~h}$, and cells were subjected to strains of $0 \mathrm{~mm}$ (control group samples), 1,333 $\mu$ (1 $\mathrm{mm})$ or 5,333 $\mu$ (4 mm). Except the degree of mechanical tensile strain, all cells received equal treatment under identical environmental conditions.

Cell proliferation analysis. Following mechanical strain, cells were washed with PBS two to three times, wiping the edge of the plate. Cells were digested with $0.25 \%$ trypsin plus EDTA, and DMEM containing 15\% FBS was added to the cell pellet following centrifugation $(200 \mathrm{x} \mathrm{g}$ at room temperature for $8 \mathrm{~min}$ ) to obtain the cell suspension, which was adjusted to 2 million cells $/ \mathrm{ml}$. The cell suspension $(100 \mu \mathrm{l} / \mathrm{well})$ was pipetted into a 96-well plate and subsequently incubated in $5 \% \mathrm{CO}_{2}$ at $37^{\circ} \mathrm{C}$ for $12-24 \mathrm{~h}$. Following this, Cell Counting kit-8 (CCK-8) solution (10 $\mu \mathrm{l} /$ well; Beyotime Institute of Biotechnology, Shanghai, China) was added to each well and incubated in 5\% $\mathrm{CO}_{2}$ at $37^{\circ} \mathrm{C}$ for $\sim 2 \mathrm{~h}$. Finally, the optical density was measured at a wavelength of $450 \mathrm{~nm}$ using a microplate reader (Victor 3; Perkin-Elmer, Waltham, MA, USA).

Immunofluorescence imaging. Following mechanical stress, cells were washed with PBS and digested with $0.25 \%$ trypsin plus EDTA. DMEM containing $15 \%$ FBS was added to the cell pellet following centrifugation $(200 \mathrm{x} \mathrm{g}$ at room temperature for $8 \mathrm{~min}$ ) to obtain the cell suspension. The cell suspension $(1 \mathrm{ml})$ was seeded into a 24 -well plate at the density of $1.5 \times 10^{5}$ cells $/ \mathrm{ml}$ and incubated for $8 \mathrm{~h}$ in $5 \% \mathrm{CO}_{2}$ at $37^{\circ} \mathrm{C}$. Following this, cells were washed three times with PBS. Paraformaldehyde phosphate buffer (Wuhan Servicebio Technology Co., Ltd., Wuhan, China) was subsequently used to fix cells. Cells were again washed three times with PBS, for 5 min each time. Phalloidin (Wuhan Servicebio Technology Co., Ltd.) was diluted to a concentration of $5 \mu \mathrm{g} / \mathrm{ml}$ using $1 \%$ bovine serum albumin (Wuhan Servicebio Technology Co., Ltd.), added to each well (100 $\mu \mathrm{l} /$ well) and plates were incubated for $30 \mathrm{~min}$ at room temperature. Following this, cells were washed three times with PBS. DAPI $(5 \mu \mathrm{g} / \mathrm{ml}, 100 \mu \mathrm{l} / \mathrm{well})$ was subsequently added to each well and incubated for $5 \mathrm{~min}$ at room temperature for nuclear staining. Cells were again washed three times with PBS, and a $2.5 \%$ glycerol mounting medium was added. Cell cytoskeletons were imaged using a fluorescence microscope (CKX31; Olympus Corporation, Tokyo, Japan).

Mitochondrial morphology observation. Primary cultured cells (passage 4-7) were seeded into three plates precoated with rat tail collagen (Sigma-Aldrich; Merck Millipore), and incubated at $5 \% \mathrm{CO}_{2}$ and $37^{\circ} \mathrm{C}$ for $\sim 24 \mathrm{~h}$. Cells were subjected to a force of $0 \mathrm{~mm}$ (control group samples), 1,333 $\mu$ (1 mm) or $5,333 \mu(4 \mathrm{~mm})$ at a fixed frequency of $0.1 \mathrm{~Hz}$ for $4 \mathrm{~h}$. Following this, cells were washed with PBS and transferred into a clean dish for treatment. A mixture of $2.5 \%$ glutaraldehyde (Servicebio of Technology) and DMEM (ratio, 1:1; $2 \mathrm{ml}$ ) was added to cells for $2 \mathrm{~min}$. Cells were subsequently centrifuged at $157 \mathrm{x} \mathrm{g}$ for $8 \mathrm{~min}$ at room temperature. The supernatant was discarded and $2.5 \%$ glutaraldehyde solution $(2 \mathrm{ml})$ was added to the cell pellet for fixation.

Following this, PBS was used to wash the cells and $1 \%$ osmium tetroxide (Wuhan Servicebio Technology Co., Ltd.) was added for fixation. Cells were dehydrated in ethanol and embedded in epoxy resin (Wuhan Servicebio Technology Co., Ltd.) for sectioning. Sections were stained with lead citrate and uranyl acetate. Alterations in mitochondrial morphology were imaged (magnification, x5,000) using a Hitachi transmission electron microscope (HT7700; Hitachi, Ltd., Tokyo, Japan).

Cell senescence. Cell senescence was assessed using the Senescence $\beta$-Galactosidase Staining kit (Beyotime Institute of Biotechnology). Following mechanical strain, cells were washed with PBS and transferred to a clean dish. $\beta$-galactosidase dye fixing solution $(1 \mathrm{ml})$ was added to cells for $15 \mathrm{~min}$ at room temperature. Following this, cells were washed three times with PBS, and $1 \mathrm{ml}$ working fluid dye $(10 \mu \mathrm{l}$ $\beta$-galactosidase staining solution $\mathrm{A}, 10 \mu \mathrm{l} \beta$-galactosidase staining solution $\mathrm{B}, 930 \mu \mathrm{l} \beta$-galactosidase staining solution $\mathrm{C}$ and $50 \mu \mathrm{l} \mathrm{X}$-Gal solution) was added. Cells were incubated at $37^{\circ} \mathrm{C}$ overnight. Images were obtained using a light microscope (BX51, Olympus Corporation, Tokyo, Japan).

Statistical analysis. Statistical analyses were performed using SPSS 16.0 (SPSS, Inc., Chicago, IL, USA), and data are presented here as the mean $\pm \mathrm{SD}$, and groups were compared using one-way analysis of variance. Differences between two groups were determined using Student's t-test, and multiple 
comparison tests were performed using Tukey's test. $\mathrm{P}<0.05$ was considered to indicate a statistically significant difference.

\section{Results}

Primary culture and identification of HPLFs. A previous study by this group identified primary cultured HPLFs as fibroblasts by immunohistochemical staining (13). The purity of fibroblasts may reach $>90 \%$ at passage $2-3$. The fibroblasts primarily appeared to possess long spindles and were closely connected when observed by light microscopy. Under mechanical stress conditions, cell morphology was altered and cell connections appeared weakened (8).

Mechanical stress reduces cell viability. The present study used CCK-8 to detect the activity and proliferation of fibroblasts. Cell viability decreased when subjected to mechanical force (Fig. 1). The optical density values following exposure to strains of $0,1,333$ or $5,333 \mu$ were $1.112 \pm 0.12,0.88 \pm 0.09$ and $0.46 \pm 0.02$, respectively. The 1,333 and $5,333 \mu$ groups demonstrated significantly reduced cell viability compared with the control group $(\mathrm{P}=0.02$ and $\mathrm{P}=0.000089$, respectively; Fig. 1). In addition, cell viability was reduced in the 5,333 $\mu$ group compared with the $1,333 \mu$ group $(\mathrm{P}=0.001$; Fig. 1$)$, indicating that cell viability decreased with increasing mechanical force.

Mechanical stress causes cytoskeleton rearrangement. In the control group, cells typically possessed long spindles, close connections to each other and uniformly distributed green fluorescence (Fig. 2, top row). Following mechanical stress loading of 1,333 (Fig. 2, middle row) or 5,333 $\mu$ (Fig. 2, bottom row), the cells demonstrated a weaker green fluorescence signal, sparser, thinner and maldistributed fasciculi, and a shrunken cell morphology. The cell cytoskeleton revealed depolymerization and rearrangement as mechanical stress increased, and cells subjected to the greatest strain $(5,333 \mu)$ demonstrated a more disordered structure.

Mechanical stress alters mitochondrial morphology. The electron microscopy images revealed that mechanical force caused vacuolization of the fibroblast mitochondria (Fig. 3). Compared with the control group, the 1,333 $\mu$ group demonstrated disappearance of mitochondrial crista and the appearance of mitochondrial vacuoles (Fig. 3B). When the mechanical stress increased to $5,333 \mu$, the complete structure of the cell was destroyed, and apoptotic bodies were observed (Fig. 3C).

Mechanical stress increases cell senescence. The present study used the $\beta$-Galactosidase Staining kit to detect the cell senescence of fibroblasts. Blue staining indicated cell senescence, with the number of stained cells increasing as the mechanical force increased (Fig. 4A-C). Cells were imaged using a light microscope (magnification, x40) and the number of senescent cells/300 cells was counted and the percentage calculated. The senescent cell percentages following exposure to strains of 0,1333 and $5,333 \mu$ were $32.41 \pm 4.17,43.89 \pm 3.47$ and $53.14 \pm 2.85 \%$, respectively (Fig. 4D). The percentage of senescent cells therefore increased with increasing mechanical force. The 1,333 and 5,333 $\mu$ groups demonstrated greater cell senescence compared with the control group $(\mathrm{P}=0.0017$ and

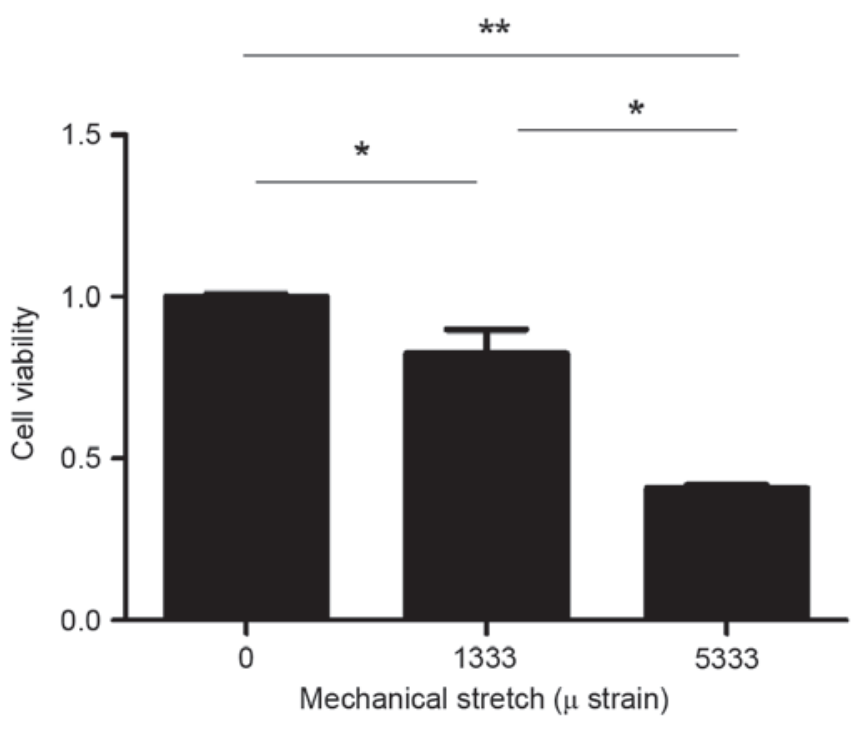

Figure 1. Mechanical stress reduces the viability of human parametrial ligament fibroblasts. Cell viability was detected by Cell Counting Kit- 8 and analyzed via the optical density value. Compared with the control group, the cell viability of the 1,333 and $5,333 \mu$ groups were significantly decreased. Data are represented as the mean \pm standard deviation $(n=3)$. ${ }^{*} \mathrm{P}<0.05$; *** $\mathrm{P}<0.01$.

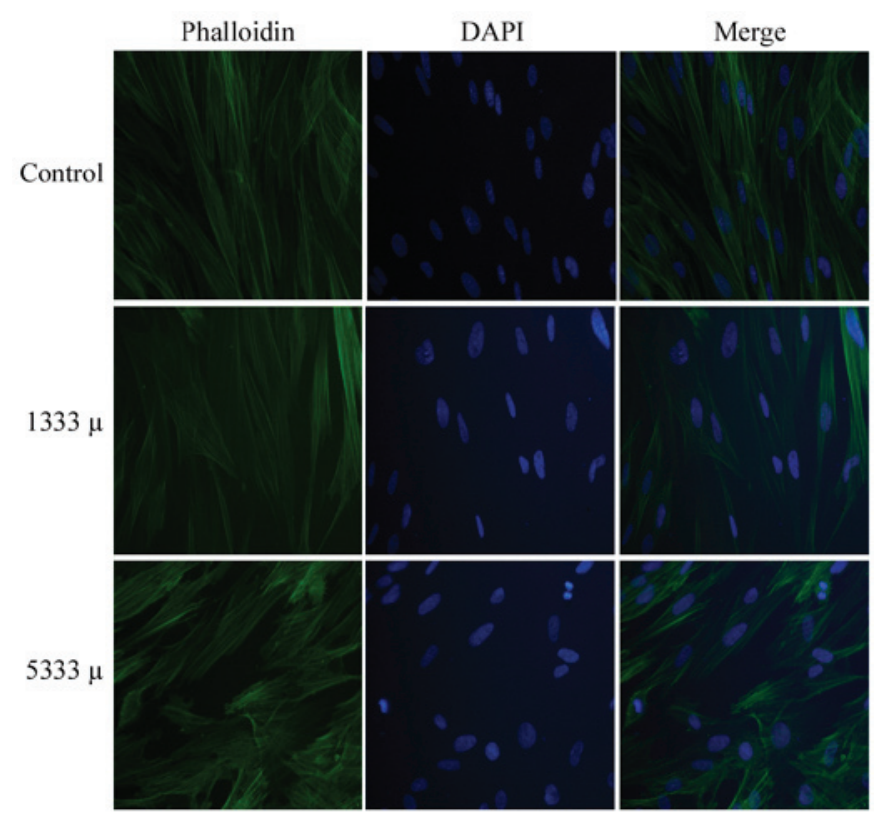

Figure 2. Mechanical stress causes cytoskeletal rearrangement in human parametrial ligament fibroblasts. Fluorescence microscopy was used to visualise the cytoskeleton using phalloidin staining, and the nucleus with DAPI staining. Compared with the control group, the 1,333 and 5,333 $\mu$ groups revealed depolymerization and rearrangement of the cell cytoskeleton. Original magnification, $\mathrm{x} 400$.

$\mathrm{P}=0.001$, respectively; Fig. 4D). In addition, there was a significantly greater percentage of senescent cells in the 5,333 $\mu$ group compared with the $1,333 \mu$ group ( $\mathrm{P}=0.042$; Fig. 4D).

\section{Discussion}

POP is a common disease in middle-aged and elderly women, which may seriously affect the physical health, mental 
A

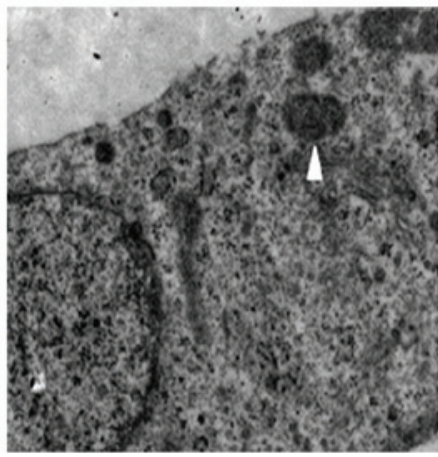

B

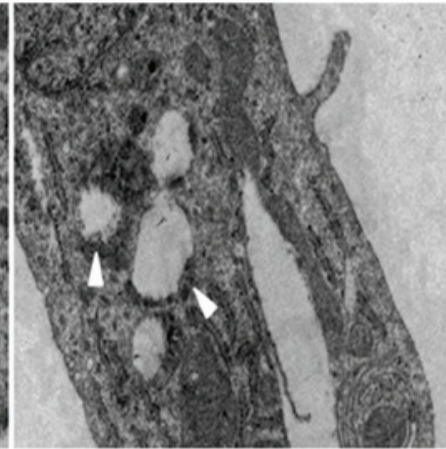

$\mathrm{C}$

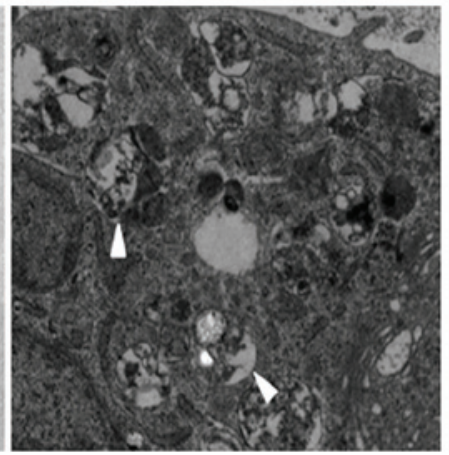

Figure 3. Mechanical stress alters mitochondrial morphology in human parametrial ligament fibroblasts. (A) Control, (B) 1,333 $\mu$ and (C) 5,333 $\mu$ groups were imaged using a transmission electron microscope. Magnification, x500. The white arrowheads indicate (A) normal mitochondria, (B) mitochondrial vacuoles and (C) apoptotic bodies.

A

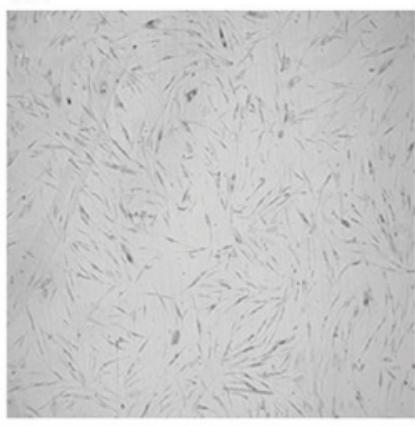

B

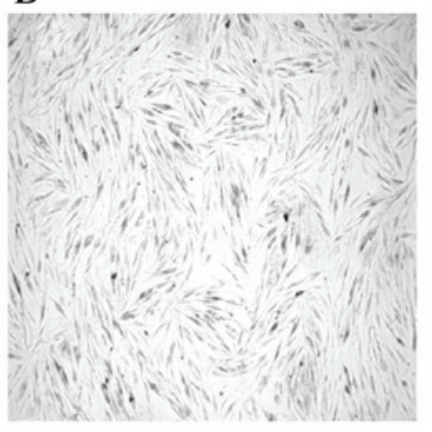

C

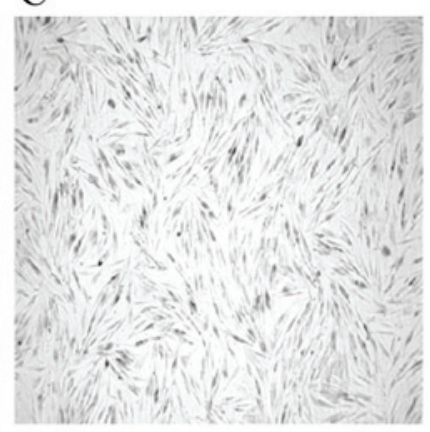

D

**

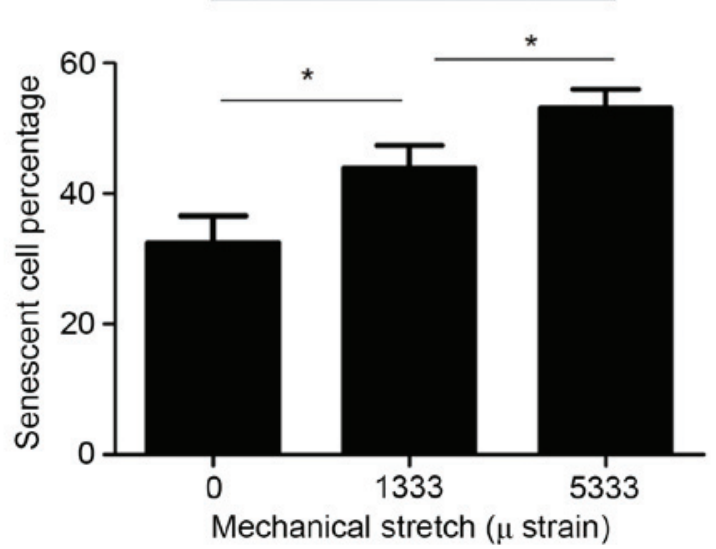

Figure 4. Mechanical stress increases the cell senescence of human parametrial ligament fibroblasts. (A) Control, (B) 1,333 $\mu$ and (C) 5,333 $\mu$ groups were imaged using a light microscope (magnification, $x 40$ ). Deep blue staining indicated senescent cells. (D) The percentage of cell senescence was quantitatively analyzed. Compared with the control group, there was a significant increase in the percentage of senescent cells in the 1,333 and 5,333 $\mu$ strain groups. This effect was more marked in the 5,333 $\mu$ strain group. Data are presented as the mean \pm standard deviation $(\mathrm{n}=3)$. ${ }^{*} \mathrm{P}<0.05$; ${ }^{* *} \mathrm{P}<0.01$.

wellbeing and quality of life of patients (14). The human parametrial ligament is the primary ligament used to maintain the normal position of the uterus, with the tissue comprising of cells and the extracellular matrix. A decrease in the mechanical properties of the human parametrial ligament may lead to POP. HPLFs respond to mechanical stimulation by synthesizing and secreting fluid into the extracellular matrix. Therefore, the present study examined cytomechanics by subjecting cells to external mechanical loading to simulate the internal environment. Whether mechanical stress influences cell proliferation, the cytoskeleton, mitochondrial alterations and cell senescence in HPLFs was investigated by inducing oxidative stress, a factor hypothesized to contribute to the development of POP. Based on our previous findings, the parameters of mechanical strain loading were set to a frequency of $0.1 \mathrm{~Hz}$ for $4 \mathrm{~h}$, and cells were subjected to strains of $0 \mathrm{~mm}, 1,333 \mu(1 \mathrm{~mm})$ and $5,333 \mu(4 \mathrm{~mm})$, to investigate the effect of mechanical force on cell injury.

Cell proliferation ability following mechanical loading was detected using a microplate reader at a wavelength of $450 \mathrm{~nm}$, 
which indicates the number of living cells. The present study demonstrated that cell viability decreased as mechanical force increased. As cell viability is an important indicator of the cellular state, this indicated that the mechanical force was damaging to HPLFs. In addition, cytoskeletal alterations were detected by immunofluorescence imaging, using phalloidin staining. The cytoskeleton is important for maintaining cell morphology, and consists of microtubules, microfilaments and intermediate filaments. Microfilaments are spiral structures composed of actin subunits, which include F- and G-actin, in dynamic equilibrium. Actin provides structural support to the cells and reacts to mechanical alterations in the surrounding environment. Lozupone et al (15) and Vico et al (16) revealed that cyclic environmental alterations may affect the structure and function of the cytoskeleton, including cytoskeletal reorganization, cytoskeletal fracture, cell dysfunction and cell death. F-actin is an important component of the cytoskeleton, and its integrity is a key factor in determining cell function (17). The present study demonstrated that the cell cytoskeleton depolymerized and rearranged with increasing mechanical force, indicating that mechanical stress may lead to F-actin damage in HPLFs.

Transmission electron microscopy was used to observe the intracellular structure and mitochondrial alterations in fibroblasts. These data demonstrated that mechanical loading may damage mitochondrial morphology. Particularly at 5,333 $\mu$, the internal structure of HPLFs was destroyed and apoptotic bodies were observed. Mitochondria are the metabolic centers of eukaryotic cells, providing basic energy to numerous types of cellular activities. They are a key factor in determining cell survival and death, and serve an important role in the transduction and expansion of death signals (18). In addition, mitochondria are the primary production site of active oxygen, and exhibit the clearest alterations and damage when cells are suffering from oxidative stress injury. Furthermore, mitochondria serve a vital role in the metabolism of free radicals, which are a further indication of cell oxidative stress. The present study revealed that an increase in mechanical force was associated with greater damage to the mitochondria of fibroblasts, consistent with a previous study, which demonstrated that mechanical loading may lead to elevated levels of intracellular oxidative stress (13). Therefore, it may be hypothesized that increased mechanical force alters mitochondrial morphology and structure by increasing the level of oxidative stress, thus affecting the function of cells. In future studies, it may be useful to further investigate the oxidative stress model, to understand whether oxidative stress may lead to structural alterations in mitochondria.

The level of cell senescence was detected using the $\beta$-galactosidase staining kit. It was revealed that the percentage of cell senescence increased as mechanical force increased. The underlying mechanisms of cellular senescence primarily include the external oxidative stress theory and the intrinsic gene regulation theory. When the body is in a state of oxidative stress, the high concentration of ROS may mediate cellular senescence by regulating associated pathways. Potential other pathways involved in oxidative stress-induced cellular senescence include the DNA-damage-response, nuclear factor- $\kappa \mathrm{B}$, mitogen-activated protein kinase and microRNA pathways $(19,20)$. Previous studies have indicated that alterations in mitochondrial structure and function are closely associated with cellular senescence (21). Furthermore, mitochondrial respiratory function, free radical scavenging ability and mitochondrial DNA mutations may mediate cell senescence (22). Therefore, it was hypothesized that the increase in cellular senescence, induced by increasing mechanical force, may be a result of damage to mitochondrial structures in the cell.

In conclusion, the present study investigated the effect of mechanical force on HPLFs at the cellular level. It was demonstrated that, with an increase of mechanical stress loading within a specific range, HPLFs began to exhibit indicators of damage, including decreased cell proliferation, increased cytoskeletal and mitochondrial injury, and increased cell senescence. These data provide a theoretical basis for further investigation into the underlying mechanisms of POP.

\section{Acknowledgements}

The present study was supported by the National Natural Science Foundation of China (grant no. 81270684) and the Foundation of Collaborative and Innovation Projects of Wuhan University School of Medicine (grant no. 523-266078).

\section{References}

1. O'Boyle AL, O'Boyle JD, Calhoun B and Davis GD: Pelvic organ support in pregnancy and postpartum. Int Urogynecol J Pelvic Floor Dysfunct 16: 69-72, 2005.

2. Gyhagen M, Bullarbo M, Nielsen TF and Milsom I: Prevalence and risk factors for pelvic organ prolapse 20 years after childbirth: A national cohort study in singleton primiparae after vaginal or caesarean delivery. BJOG 120: 152-160, 2013.

3. Rodrigues AM, de Oliveira LM, Martins Kde F, Del Roy CA, Sartori MG, Girão MJ and Castro Rde A: Risk factors for genital prolapse in a Brazilian population. Rev Bras Ginecol Obstet 31: 17-21, 2009 (In Portuguese).

4. Jones KA and Moalli PA: Pathophysiology of pelvic organ prolapse. Female Pelvic Med Reconstr Surg 16: 79-89, 2010.

5. Gutierrez C, Corbera JA, Morales I, Morales M and Navarro R: Uterine prolapse in 2 dromedary camels. Can Vet J 42: 803-804, 2001.

6. Kim EJ, Chung N, Park SH, Lee KH, Kim SW, Kim JY, Bai SW and Jeon MJ: Involvement of oxidative stress and mitochondrial apoptosis in the pathogenesis of pelvic organ prolapse. J Urol 189: 588-594, 2013

7. Li BS, Hong L, Min J, Wu DB, Hu M and Guo WJ: The expression of glutathione peroxidase- 1 and the anabolism of collagen regulation pathway transforming growth factor-betal-connective tissue growth factor in women with uterine prolapse and the clinic significance. Clin Exp Obstet Gynecol 40: 586-590, 2013.

8. Hong S, Li H, Wu D, Li B, Liu C, Guo W, Min J, Hu M, Zhao Y and Yang Q: Oxidative damage to human parametrial ligament fibroblasts induced by mechanical stress. Mol Med Rep 12: 5342-5348, 2015

9. Lu M, Gong X, Lu Y, Guo J, Wang C and Pan Y: Molecular cloning and functional characterization of a cell-permeable superoxide dismutase targeted to lung adenocarcinoma cells. Inhibition cell proliferation through the Akt/p27kip1 pathway. J Biol Chem 281: 13620-13627, 2006.

10. Matthews BD, Overby DR, Alenghat FJ, Karavitis J, Numaguchi Y, Allen PG and Ingber DE: Mechanical properties of individual focal adhesions probed with a magnetic microneedle. Biochem Biophys Res Commun 313: 758-764, 2004.

11. Kapeta S, Chondrogianni N and Gonos ES: Nuclear erythroid factor 2-mediated proteasome activation delays senescence in human fibroblasts. J Biol Chem 285: 8171-8184, 2010.

12. Bao R, Liu $X$ and Zhou J: Primary culture and identification of human fibroblasts. J XinX Med Coll 5: 015, 2011 (In Chinese). 
13. Ding WJ, Fang G, Hong Li, Hong SS, Hu M, Min J, Wu DB, Yang Q, Zhang XH and Zhao Y: Effects of oxidative damage in human parametrial ligament fibroblasts induced by mechanical stress. Chinese Journal of Clinicians 23: 10775-10779, 2013 (In Chinese).

14. Chen Y and Yuan M: Progress in research on pathogenesis of pelvic organ prolapsed. Chinese Journal of Woman and Child Health Research 19: 507-509, 2008 (In Chinese).

15. Lozupone E, Favia A and Grimaldi A: Effect of intermittent mechanical force on bone tissue in vitro: Preliminary results. J Bone Miner Res 7 (Suppl 2): S407-S409, 1992.

16. Vico L, Lafage-Proust MH and Alexandre C: Effects of gravitational changes on the bone system in vitro and in vivo. Bone 22 (Suppl 5): 95S-100S, 1998.

17. Stricker J, Falzone T and Gardel ML: Mechanics of the F-actin cytoskeleton. J Biomech 43: 9-14, 2010.

18. Sims NR and Muyderman H: Mitochondria, oxidative metabolism and cell death in stroke. Biochim Biophys Acta 1802: 80-91, 2010 .
19. Rai P, Onder TT, Young JJ, McFaline JL, Pang B, Dedon PC and Weinberg RA: Continuous elimination of oxidized nucleotides is necessary to prevent rapid onset of cellular senescence. Proc Natl Acad Sci USA 106: 169-174, 2009.

20. Ito K, Hirao A, Arai F, Takubo K, Matsuoka S, Miyamoto K, Ohmura M, Naka K, Hosokawa K, Ikeda Y and Suda T: Reactive oxygen species act through p38 MAPK to limit the lifespan of hematopoietic stem cells. Nat Med 12: 446-451, 2006.

21. Booth FW: Perspectives on molecular and cellular exercise physiology. J Appl Physiol (1985) 65: 1461-1471, 1988.

22. Lustbader JW, Cirilli M, Lin C, Xu HW, Takuma K, Wang N, Caspersen C, Chen X, Pollak S, Chaney M, et al: ABAD directly links Abeta to mitochondrial toxicity in Alzheimer's disease. Science 304: 448-452, 2004. 